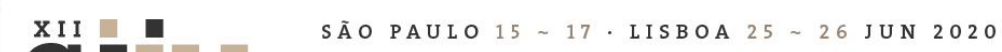

\section{PARQUE OLÍMPICO DO RIO DE JANEIRO: Análise da percepção de segurança, da localização e dos usos no período pós-jogos}

\section{RIO DE JANEIRO OL YMPIC PARK: Analysis of the perception of security, location and uses in the post- game period}

\author{
A. Gabriela Silva \& B. Antônio Tarcísio Reis \\ Universidade Federal do Rio Grande do Sul, Brasil \\ gs.arq@hotmail.com.br \\ tarcisio@orion.ufrgs.br
}

\section{RESUMO}

Este artigo tem o objetivo de investigar os usos dos equipamentos do Parque Olímpico do Rio de Janeiro, no período pós-jogos, em função da percepção de segurança e da localização, através de usuários e funcionários desses equipamentos. Os dados foram coletados através de 24 entrevistas estruturadas, $20 \mathrm{com}$ usuários e quatro com funcionários do Parque Olímpico. Os usuários foram contatados nas Arenas Cariocas 1 e 3 e no Centro de Tênis. Os funcionários foram contatados nos equipamentos do Parque Olímpico no horário comercial dos dias de semana. As entrevistas foram gravadas e, posteriormente, transcritas. Os dados foram analisados conforme a frequência, o significado e a importância dos pontos mencionados pelos entrevistados. Os resultados evidenciam, por exemplo, que a disponibilidade de transporte público reduz problemas gerados pela distância entre os equipamentos e a moradia dos usuários e que a segurança contribui para o uso dessas instalações.

Palavras-chave: equipamento olímpico, Parque Olímpico, uso pós-jogos.

Linha de Investigação: 1: Cidade e projeto. Tópico: Projeto urbano e espaço público.

\section{ABSTRACT}

This paper aims to investigates the use of the equipment at the Rio de Janeiro Olympic Park, in the postgames period, according to the perception of security and location, through users and employees of these equipment. Data were collected through 24 structured interviews, 20 with users and four with Olympic Park employees. The users were contacted at Arenas Cariocas 1 and 3 and at the Tennis Center. The employees were contacted on the Olympic Park equipment during business hours on weekdays. The interviews were recorded and later transcribed. The data were analyzed according to the frequency, the meaning and the importance of the points mentioned by the interviewees. The results evidence, for example, that the availability of public transportation reduces problems generated by the distance between the equipment and the users' place of residence and that safety contributes to the use of these facilities. 


\section{Introdução}

Os equipamentos olímpicos estão diretamente relacionados ao legado deixado pelas Olimpíadas após o término dos jogos (Ritchie, 2000). No entanto, para que este legado seja considerado sustentável, os equipamentos precisam ser utilizados pela população local e por atletas de alto rendimento (Cashman, 2012; Davies, 2012). Contudo, equipamentos olímpicos tem sido abandonados ou subtilizados após diferentes edições do megaevento, tais como no Parque Olímpico de Atenas 2004 e de Pequim 2008 (Panagiotopoulou, 2014; Mascarenhas, 2014). Neste sentido, a baixa porcentagem de equipamentos olímpicos utilizados de modo satisfatório no período pós-jogos (Cashman, 1998; Roult; Lefebvre, 2010), revela um problema comum às diferentes cidades-sede das últimas décadas (Essex; Chalkley, 2003 apud Toohey, 2008), indicando que o planejamento para o uso pós-jogos dos equipamentos olímpicos deve ser considerado pelos organizadores do megaevento (Smith, 2014).

Por sua vez, o Comitê Olímpico Internacional (COI) recomenda que equipamentos para modalidades esportivas sem tradição na cidade-sede ou que não seriam adequados para alojar alguma atividade benéfica para a população local devem ser construídos de forma temporária, desmontados após os jogos (IOC, 2017). Por outro lado, o $\mathrm{COI}$ aconselha que os equipamentos permanentes, aqueles a serem mantidos após os jogos, devem ter os seus usos planejados para este período, visando atender as necessidades de atletas e da população através de incentivos à prática esportiva e da criação de eventos diversos $(I O C, 2015)$. Neste sentido, destaca-se a necessidade de uma forma balanceada da gestão dos equipamentos no período pósjogos, "atendendo não apenas às exigências específicas do esporte e aos interesses particulares de grupos e setores. É também fundamental contemplar o desenvolvimento sustentável e atender as necessidades da sociedade civil' (Rodrigues; Pinto, 2008: p.24).

Entretanto, não existem orientações mais detalhadas sobre aspectos que afetam os possíveis usos, ou sobre os próprios usos dos diversos equipamentos olímpicos permanentes no período pós-jogos, tanto por parte do $\mathrm{COI}$ quanto por parte dos comitês organizadores das cidades-sede. Sem focar em tais aspectos, os resultados do estudo de Azzali (2017) acerca do uso do Parque Olímpico de Londres estão em sintonia com as recomendações dadas pelo $\mathrm{COI}$ ao revelar que a diversidade de atividades oferecidas pelos equipamentos olímpicos no período pós-jogos atendem as necessidades da população. O estudo conclui que o Parque Olímpico de Londres é altamente utilizado, principalmente, para fins recreativos por famílias, jovens, mães e crianças, durante o verão.

Todavia, não têm sido encontrados estudos específicos sobre os usos de equipamentos olímpicos no período pós-jogos em função da localização, com exceção de um estudo (Silva; Reis, 2018) sobre a relação entre usos no período pós-jogos e acessibilidade. Este estudo mostra a percepção de acessibilidade adequada da área olímpica em Deodoro, por usuários e moradores do entorno, em função da proximidade de uma via expressa importante (Av. Brasil) e da percepção de acessibilidade adequada da área olímpica na Barra da Tijuca apenas pelos moradores do entorno, uma vez que seus usuários moravam a $39 \mathrm{~km}$ do Parque Olímpico. Contudo, existe a necessidade de confirmação destes resultados, uma vez que somente quatro usuários haviam sido entrevistados.

Por sua vez, a percepção de insegurança e medo também pode afetar o uso de equipamentos olímpicos no período pós-jogos, pois as pessoas tendem a evitar espaços percebidos como inseguros (Jacobs, 2014; Francis, 2003). Neste sentido, a partir de 32 entrevistas com usuários do Parque Olímpico do Rio de Janeiro, 


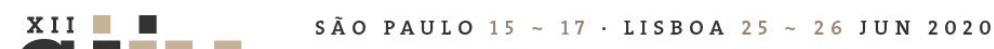

o estudo realizado por Bertuzzi e Cardoso (2018) identifica que embora estes entrevistados tenham demonstrado a necessidade de intensificar a segurança no interior do parque através de mais policiamento, nenhum deles teve conhecimento da ocorrência de crimes. Contudo, este estudo não trata da relação entre a percepção de segurança e o uso dos equipamentos olímpicos.

Portanto, existe a necessidade de investigar, de maneira mais sistemática e aprofundada, os níveis de utilização de cada equipamento no Parque Olímpico do Rio de Janeiro, assim como os efeitos da percepção de segurança e da localização por parte de distintos grupos. Assim, é objetivo desta pesquisa investigar os usos dos equipamentos do Parque Olímpico do Rio de Janeiro, no período pós-jogos, em função da percepção de segurança e da localização, através de usuários e funcionários desses equipamentos.

\section{Metodologia}

O Parque Olímpico do Rio de Janeiro está localizado no bairro Barra da Tijuca (Fig. 1), zona oeste da cidade, a $33 \mathrm{~km}$ do centro. Este bairro, caracterizado como área de expansão (Comitê de Candidatura Rio 2016, 2009a) de grande demanda imobiliária (Comitê de Candidatura Rio 2016, 2009b), possui tendência para investimentos desde a década de 1970 com o desenvolvimento do Plano Piloto da Baixada de Jacarepaguá e vem se consolidando com o apoio de megaeventos e seus altos investimentos desde os Jogos Pan Americanos 2007 (Monteiro; Cosentino, 2017). A Barra da Tijuca abriga 5\% da população do Rio de Janeiro, com o predomínio de pessoas com faixa etária entre 35 e 49 anos, seguido de pessoas entre 50 e 69 anos. O rendimento nominal mensal domiciliar é, fundamentalmente, maior que 20 salários mínimos (IBGE, 2010), o que permite caracterizar o bairro como de alto poder aquisitivo (Pasquotto, 2016).

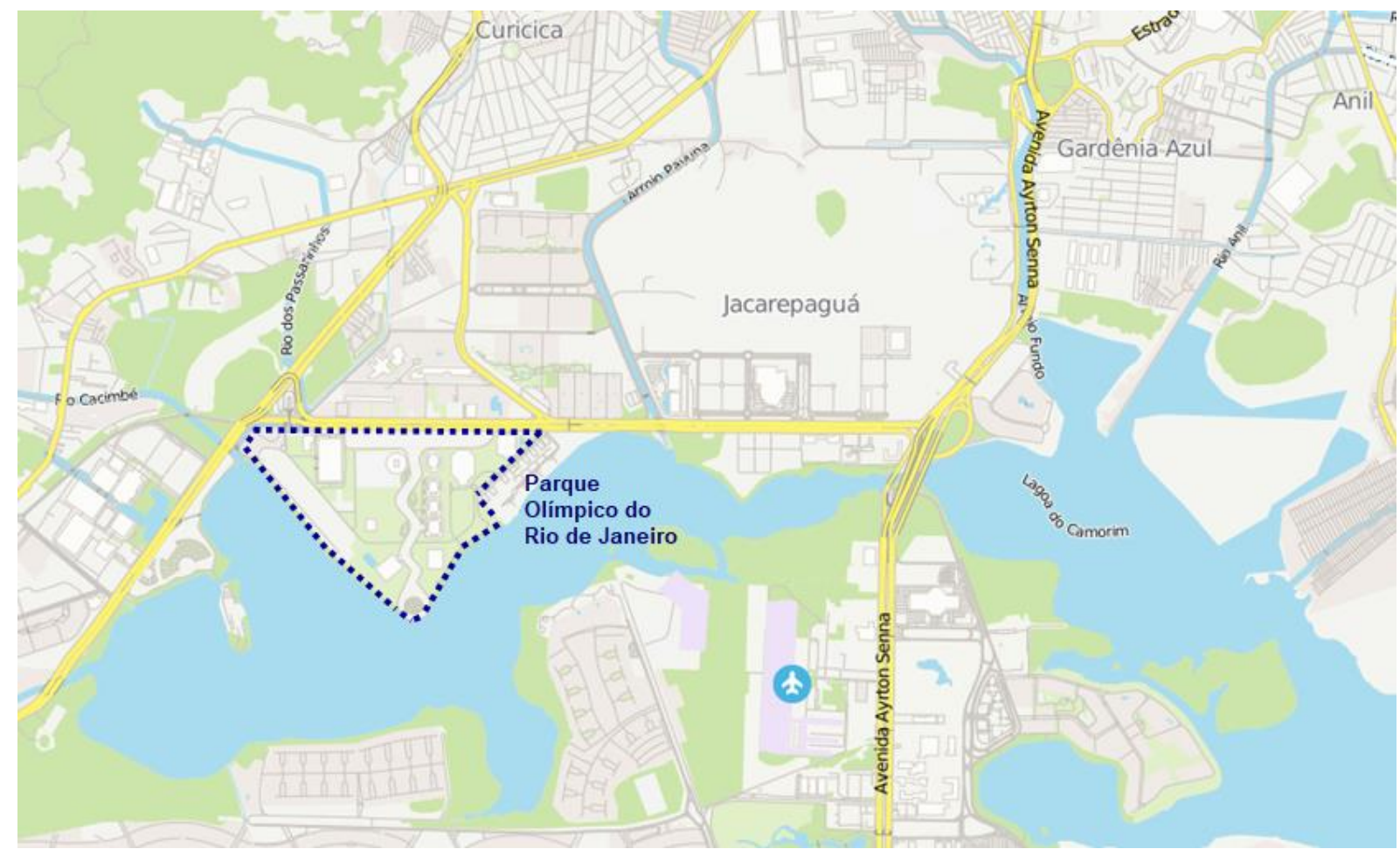

Fig. 1: Localização do Parque Olímpico do Rio de Janeiro. Fonte: (Elaborado pela autora com base no Moovit, 2019). 


\section{Siliul. \\ SÃO PAULO 15 17. LISBOA $25 \sim 26$ JUN 2020 \\ Seminário Internacional de \\ Investigação em Urbanismo \\ Seminario Internacional de Investigación en Urbanismo}

dúvidas, em consequência da interação com o entrevistado (Reis; Lay, 1995). As entrevistas foram realizadas com usuários e funcionários do Parque Olímpico do Rio de Janeiro entre 7 e 26 de novembro de 2019, em um total de 24, sendo $20 \mathrm{com}$ usuários e quatro com os funcionários do Parque Olímpico. Os usuários (Tabela 2) foram entrevistados in loco na Arena Carioca 1 e no Centro de Tênis em dias de evento (Competição de Judô e Jogo de Futebol da Copa Carioquinha Dente de Leite) e na academia localizada dentro da Arena Carioca 3 (Tabelas 3). Os funcionários foram entrevistados nos equipamentos do Parque Olímpico pelos quais eram responsáveis durante os dias de semana em horário comercial, conforme segue: um Supervisor de Sistemas do Velódromo do Centro de Tênis e das Arenas Cariocas 1 e 2, entrevistado nesta última; um administrador do Velódromo; um Coordenador de eventos e um Gerente de eventos da Arena Carioca 3 (Tabela 4). Ainda, as entrevistas foram gravadas mediante autorização dos participantes, e, posteriormente, transcritas. A partir da categorização das informações obtidas nas entrevistas, os dados foram analisados de acordo com a frequência, o significado e a importância dos pontos mencionados pelos entrevistados.

\begin{tabular}{|c|c|c|c|c|c|c|c|c|c|c|}
\hline \multicolumn{4}{|c|}{ Faixa etária (\%) } & \multicolumn{4}{|c|}{ Renda (\%) } & \multicolumn{3}{|c|}{$\begin{array}{c}\text { Distância da moradia até o Parque } \\
\text { Olímpico }(\%)\end{array}$} \\
\hline $\begin{array}{l}\text { De } 14 \text { a } \\
18 \text { anos }\end{array}$ & $\begin{array}{l}\text { De } 19 \text { a } \\
30 \text { anos }\end{array}$ & $\begin{array}{l}\text { De } 31 \text { a } \\
65 \text { anos }\end{array}$ & $\begin{array}{l}\text { Mais de } \\
65 \text { anos }\end{array}$ & $\begin{array}{l}\text { Até } 2 \\
\text { SM }\end{array}$ & $\begin{array}{l}\text { Entre } 2 \\
\text { e } 5 \text { SM }\end{array}$ & $\begin{array}{l}\text { Entre } 5 \\
\text { e } 10 \text { SM }\end{array}$ & $\begin{array}{l}\text { Entre } 10 \\
\text { e } 20 \text { SM }\end{array}$ & Até $2 \mathrm{~km}$ & $\begin{array}{l}\text { Entre } 5 \mathrm{~km} \mathrm{e} \\
10 \mathrm{~km}\end{array}$ & $\begin{array}{l}\text { Entre } 25 \mathrm{~km} \\
\text { e } 40 \mathrm{~km}\end{array}$ \\
\hline $3(15)$ & $6(30)$ & $6(30)$ & $5(25)$ & $3(15)$ & $10(50)$ & $1(5)$ & $2(10)$ & $6(40)$ & $4(10)$ & $10(50)$ \\
\hline
\end{tabular}

Nota: SM: Salário mínimo do Censo IBGE de $2010(\mathrm{R} \$ 510,00)$.

Tabela 2: Faixa etária, nível de renda, e distância da moradia dos usuários do Parque Olímpico. Fonte: (Autor).

\begin{tabular}{c|c|c}
\hline Equipamento Olímpico & Atividade & Número de usuários entrevistados \\
\hline Arena Carioca 1 & Competição de Judô & 7 \\
\hline Arena Carioca 3 & Academia (treinar) & 7 \\
\hline Centro Olímpico de Tênis & Jogo de Futebol da Copa Carioquinha & 6 \\
\hline
\end{tabular}

Tabela 3: Usuários entrevistados em cada equipamento olímpico. Fonte: (Autor).

\begin{tabular}{c|c|c}
\hline $\begin{array}{c}\text { Cargo e função do funcionário } \\
\text { entrevistado }\end{array}$ & Equipamento Olímpico & \multirow{2}{*}{ Ano que iniciou o trabalho } \\
\cline { 1 - 2 } Supervisor de sistemas & Arena Carioca 1 & \\
\cline { 2 - 3 } & Arena Carioca 2 & \\
\cline { 2 - 3 } & Centro Olímpico de Tênis \\
\hline Administrador & Velódromo & 2015 \\
\hline Coordenador de eventos & Arena Carioca 3 & 2017 \\
\hline Gerente de eventos & Arena Carioca 3 & 2017 \\
\hline
\end{tabular}

Tabela4: Amostra dos funcionários entrevistados no Parque Olímpico do Rio de Janeiro. Fonte: (Autor). 


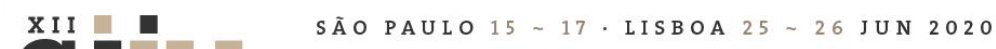

\section{Resultados}

Conforme os objetivos da pesquisa, são apresentados, a seguir, os resultados.

\subsection{Velódromo: percepção de segurança, localização e usos}

O Velódromo e seu entorno são percebidos como muito seguros pelos dois funcionários entrevistados, por desconhecerem a ocorrência de algum crime. Da mesma forma, oito usuários do Velódromo, dentre os 20 entrevistados, o consideraram seguro, bem como o seu entorno, por não terem sido vítimas ou nem possuírem conhecidos que tenham sido vítimas de crimes. Embora os dois funcionários entendam que o equipamento está localizado em uma área de fácil acesso pelo BRT, para um deles o Parque Olímpico fica afastado das demais áreas da cidade e as pessoas demoram para chegar ao local. Dentre os oito usuários do Velódromo, sete consideram sua localização adequada por ser acessível por meio de transporte público, fundamentalmente, BRT, por estar em uma área com infraestrutura tal como a presença de hotéis e avenidas e calçadas adequadas, e por ser segura, enquanto um a considera nem adequada nem inadequada devido ao equipamento estar localizado em uma área afastada de sua moradia, o que reflete o fato que seis usuários moram entre $25 \mathrm{~km}$ e $40 \mathrm{~km}$ do Parque Olímpico e dois moram entre $5 \mathrm{~km}$ e $10 \mathrm{~km}$.

Por sua vez, conforme os dois funcionários entrevistados, o Velódromo é bem utilizado em razão do seu uso diário para o treinamento de ciclismo da seleção brasileira e argentina e por abrigar o projeto 'Brincando com o esporte'. Para este projeto, que atende crianças e jovens/adolescentes do Rio de Janeiro, o Velódromo é adaptado para abrigar aulas de vôlei, futebol, capoeira, judô e jiu-jitsu. Estas aulas acontecem de terça-feira à sexta-feira das $8 \mathrm{~h}$ às $19 \mathrm{~h}$ em uma parceria do Governo Federal com a Universidade Federal Fluminense. Principalmente aos finais de semana, campeonatos de jiu-jitsu, judô, tênis de mesa e patins, por exemplo, tendem a ocorrer no Velódromo, potencializando seu uso. Nesse sentido, oito usuários do Parque Olímpico frequentam o Velódromo para participar e assistir campeonatos de judô, jiu-jitsu e ginástica artística, os quais são abertos à população (Fig. 3). Conforme um dos usuários entrevistados, "eu venho todos os meses para competir. Antes da construção do Parque Olímpico a gente ia competir em Campo Grande e podendo treinar aqui, facilitou". Ainda, segundo outro usuário "antes da construção do Parque Olímpico os campeonatos aconteciam em Deodoro, em um local sem infraestrutura boa. A construção desta instalação melhorou bastante a realização dos eventos". Assim, o Velódromo recebe adaptações para abrigar alguns dos esportes mencionados acima, mas também é utilizado para o seu uso original estabelecido nas Olimpíadas (Tabela 1). 


\section{XII $\square$ SÃOPAULO15 17 LISBOA $25 \sim 26$ JUN 2020

Arena Carioca 1 recebe adaptações para abrigar alguns dos esportes mencionados acima, mas também é utilizada para jogos de basquete, uma das modalidades estabelecidas nas Olimpíadas (Tabela 1).

Assim, a Arena Carioca 1 é bem utilizada no período pós-jogos e a percepção de segurança favorece este uso. No entanto, a localização deste equipamento não auxilia no seu uso, pois a maior parte dos seus usuários mora distante do Parque Olímpico. Logo, a proximidade da Arena Carioca 1 aos locais de moradia dos principais usuários incrementaria seu uso no período pós-Olimpíada.

\subsection{Arena Carioca 2: percepção de segurança, localização e usos}

A Arena Carioca 2 e o seu entorno são percebidos pelo funcionário entrevistado como muito seguros por não ter o conhecimento da ocorrência de crimes. Apesar da localização deste equipamento ser considerada adequada pelo funcionário devido à sua acessibilidade, sobretudo, pelo BRT, ele a considera distante das demais áreas da cidade. Este também entende que a Arena Carioca 2 é bem utilizada, uma vez que o local funciona como Centro de Treinamento para diferentes modalidades esportivas (Fig. 5), além de abrigar eventos esportivos ( jogos promovidos pela Universidade Federal Fluminense: judô, jiu-jitsu, basquete, vôlei e futsal) e não esportivos (feiras, evento de games, Rock in Rio, evento gastronômico, projeto PCD - Pessoas Com Deficiência). Contudo, em razão desta Arena ser utilizada para o Rock in Rio, a cada dois anos, e para o Game XP, uma vez ao ano, o funcionário destaca que "não tem como um esportista de alto rendimento (...) parar o treinamento por muito tempo por conta destes eventos. Então, a gente quer passar tudo para o Velódromo, que é menos utilizado para o Game XP, por exemplo". Logo, a Arena Carioca 2 recebe adaptações para abrigar esportes e eventos mencionados acima, mas também é utilizada para competições de judô, uma das modalidades estabelecidas nas Olimpíadas (Tabela 1).

Assim, conforme o funcionário entrevistado, este equipamento é bem utilizado no período pós-jogos e a percepção de segurança favorece este uso. Contudo, não há evidências sobre seu uso em função da percepção de segurança e da avaliação da localização por parte dos usuários, uma vez que dentre os 20 usuários do Parque Olímpico entrevistados, nenhum frequenta a Arena Carioca 2.

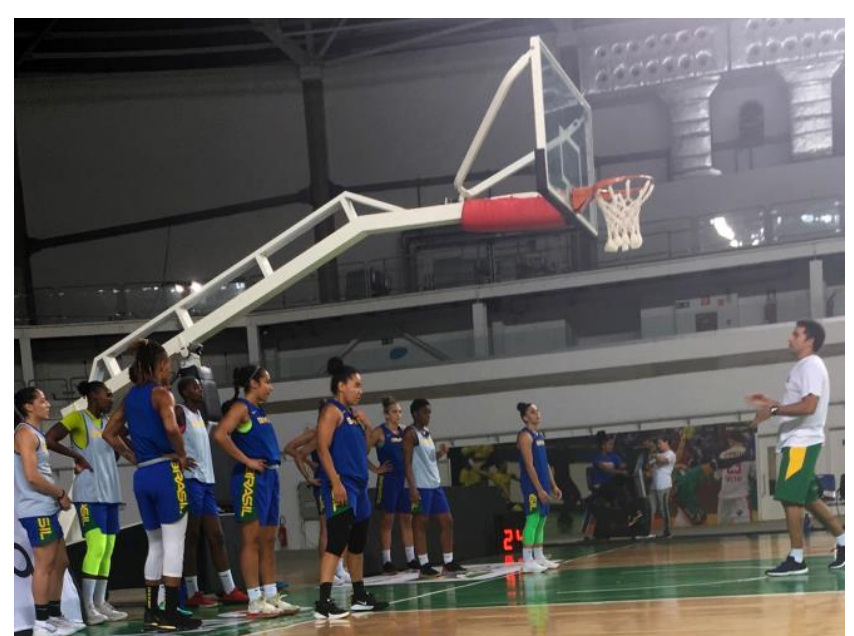

Fig. 5: Treino de Basquete na Arena Carioca 2. Fonte: (Autor, 2019).

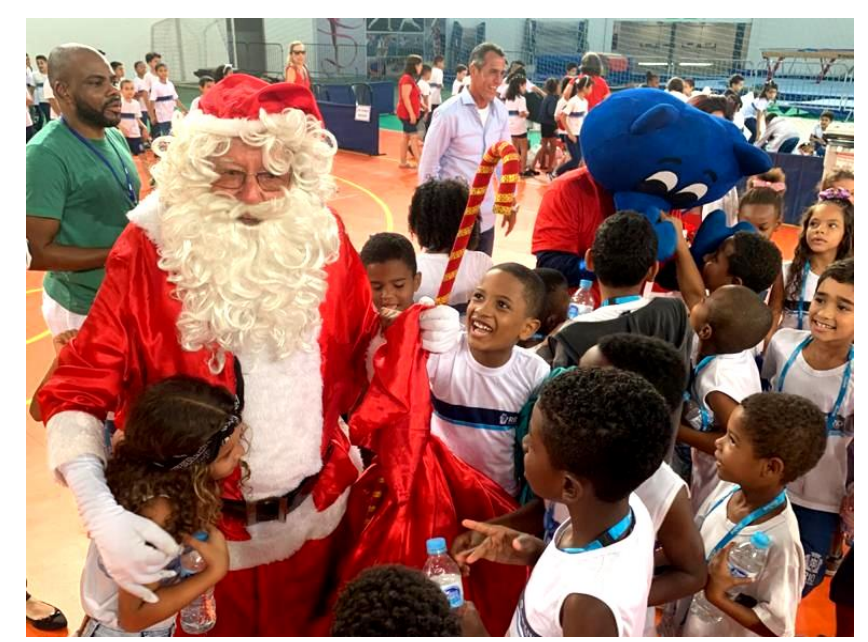

Fig. 6: Chegada do Papai Noel na Arena Carioca 3. Fonte: (Prefeitura do Rio de Janeiro, 2019). 


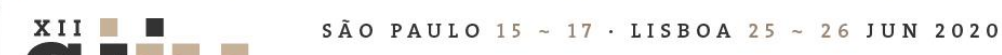

\subsection{Arena Carioca 3: percepção de segurança, localização e usos}

A Arena Carioca 3 e seu entorno são percebidos como seguros pelos dois funcionários entrevistados, pois além de não terem sido vítimas de crimes, a Guarda Municipal faz a vigilância do entorno. Contudo, um dos funcionários afirma que em alguns eventos, como Rock in Rio, há relatos de roubos e que "já houve casos isolados do pessoal entrar nos equipamentos que vão ser desmontados para roubar cabos". Dentre os sete usuários deste equipamento, seis o consideraram seguro, bem como o seu entorno, por não terem sido vítimas ou nem possuírem conhecidos que tenham sido vítimas de crimes, e um usuário considera o entorno inseguro por não haver policiamento. A localização da Arena Carioca 3 é considerada adequada pelos dois funcionários entrevistados em função da área ser segura e acessível, fundamentalmente, pelo BRT, enquanto os sete usuários desta Arena consideram sua localização adequada devido ao fato de estar em uma região previamente carente de espaços de lazer e esporte, e do local ser acessível a partir de outras partes da cidade.

Segundo os dois funcionários entrevistados, a Arena Carioca 3 é bem utilizada, pois entre agosto de 2017 e novembro de 2019 esta Arena recebeu 223 eventos esportivos (judô, jiu-jitsu, badminton, tênis de mesa, futsal, ginástica artística, vôlei e basquete), 52 eventos diversos (Rock in Rio e Game XP, por exemplo) e 15 comunitários e de lazer (chegada do Papai Noel para as crianças da rede pública de ensino, por exemplo) (Fig. 6). Conforme um dos funcionários, entre 2018 e 2019 a Prefeitura possuía parceria com o SESC Rio, proporcionando atividades esportivas (tênis de mesa, musculação, circuito), culturais (artesanato) e educacionais (aulas de inglês e espanhol) na Arena Carioca 3. Todavia, com as interrupções dessas atividades para a realização de grandes eventos (Rock in Rio e Game XP), no segundo semestre de 2019, o SESC suspendeu suas atividades nesta Arena. Por sua vez, sete usuários frequentam a Arena Carioca 3 para ir na academia duas vezes por semana (Fig. 7) e seis afirmaram que as atividades disponibilizadas pelo SESC eram muito benéficas para a população por trabalhar com diferentes faixas etárias e proporcionar qualidade de vida. De acordo com um usuário:

Eu fazia todas atividades que eram possíveis, como atividades para a memória, onde a professora te ajudava a ativar memória, lembranças que você tinha perdido, aulas de espanhol e inglês (...) isso para a autoestima é maravilhoso. Eu diminuí os meus remédios, algumas pessoas pararam de tomar remédios para depressão, porque isso eleva sua autoestima, saúde, disposição. Você fica alegre.

Contudo, conforme um dos funcionários entrevistados, não havia previsão ou o conhecimento das atividades do SESC voltarem a acontecer. Ainda, a Arena Carioca 3 abriga modalidades esportivas distintas daquelas que ocorreram durante as Olimpíadas (esgrima, taekwondo e vôlei sentado - Tabela 1). Portanto, a Arena Carioca 3 é bem utilizada no período pós-jogos e a percepção de segurança dos seus usuários e a sua localização favorecem este uso, uma vez que seus usuários são moradores do entorno. No entanto, durante o período das entrevistas, não ocorreram eventos abertos à população que pudessem atrair pessoas de outras áreas da cidade. 


\section{XII $\square$ SÃOPAULO15 17 LISBOA $25 \sim 26$ JUN 2020 \\ Seminário Internacional de Seminario Internacional de Investigação em Urbanismo Investigación en Urbanismo}

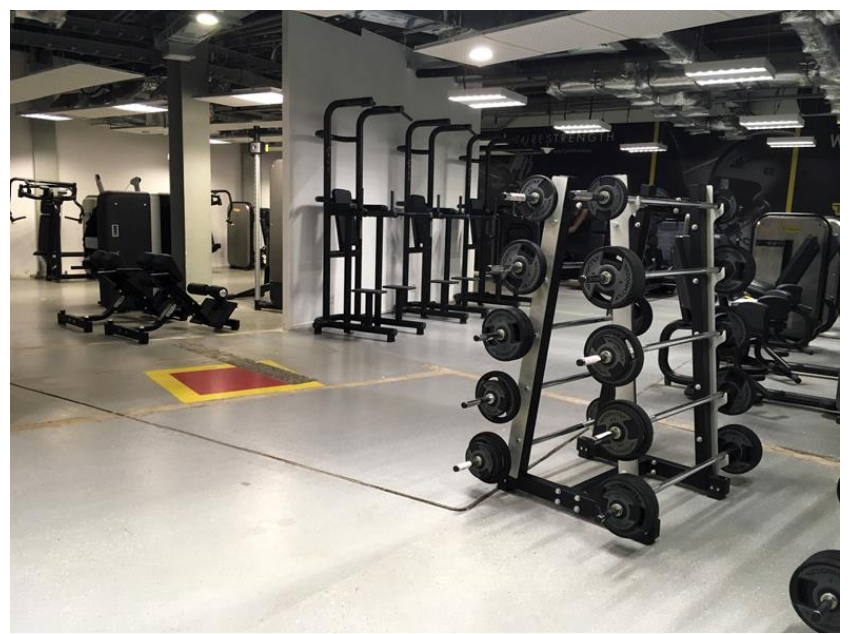

Fig. 7: Academia localizada na Arena Carioca 3. Fonte: (Autor, 2019).

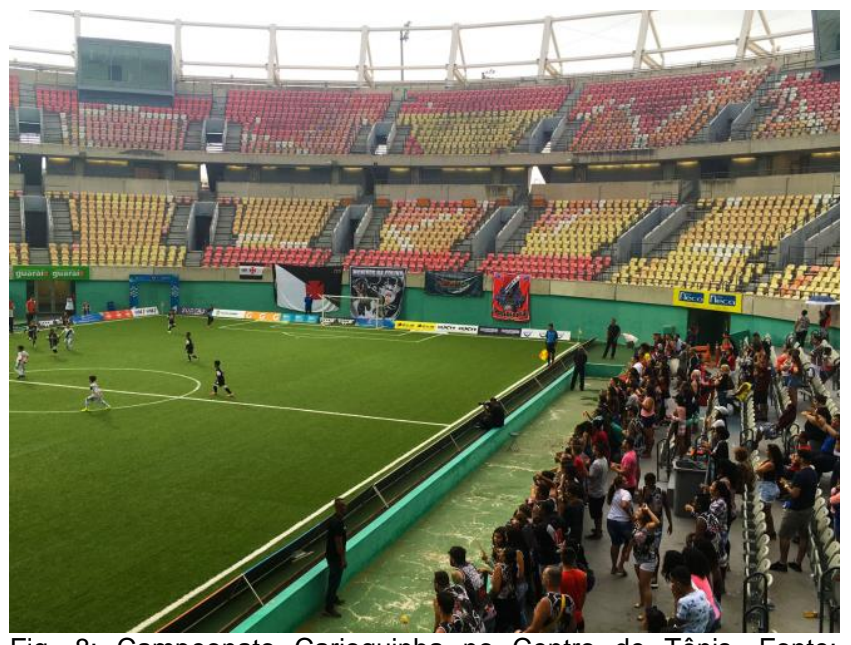

Fig. 8: Campeonato Carioquinha no Centro de Tênis. Fonte: (Autor, 2019).

\subsection{Centro de Tênis: percepção de segurança, localização e usos}

O Centro de Tênis e seu entorno são percebidos como muito seguros pelo funcionário entrevistado por desconhecer a ocorrência de algum crime. Da mesma forma, seis usuários do Centro de Tênis, dentre os 20 entrevistados, o consideraram seguro, assim como o seu entorno, por não terem sido vítimas ou nem possuírem conhecidos que tenham sido vítimas de crimes. Ainda que a localização do Centro de Tênis seja considerada adequada pelo funcionário em função de sua acessibilidade, sobretudo, pelo BRT, ele a considera afastada das demais áreas da cidade. Os seis usuários entrevistados consideram adequada a localização do Centro de Tênis devido à sua proximidade com a estação de BRT e com a Avenida Transolímpica, construída para as Olimpíadas. Todavia, dois destes afirmam haver falta de sinalização de acesso ao equipamento. Conforme um dos usuários "a presença de BRT e da estação próxima ao Parque Olímpico não tem atrapalhado o acesso de quem mora distante", o que reflete o fato que cinco usuários moram entre $25 \mathrm{~km}$ e $40 \mathrm{~km}$ do Parque Olímpico e um mora entre $5 \mathrm{~km}$ e $10 \mathrm{~km}$.

Segundo o trabalhador entrevistado, o Centro de Tênis "não possui uso suficiente e falta explorar o seu potencial", pois o equipamento é pouco utilizado, principalmente, para a prática de sua modalidade. Apesar disso, o local abriga o projeto 'Brincando com o Esporte' que acontece em dois dias da semana. Em 2019 o local foi modificado de modo temporário para abrigar a Copa Carioquinha Dente de Leite, campeonato da Federação do Estado do Rio de Janeiro que engloba crianças de até 10 anos de todas as escolinhas de futebol da cidade. Adicionalmente, as quadras externas são utilizadas, com menos intensidade, para treinos da seleção de tênis e pela comunidade por meio de um projeto chamado 'Atleta.co', onde a pessoa agenda $1 \mathrm{~h}$ de treino via internet (https://rio.atleta.co/). Por sua vez, seis usuários frequentam o Centro de Tênis para assistir o Campeonato Copa Carioquinha Dente de Leite aos finais de semana. Contudo, antes deste campeonato nenhum dos entrevistados frequentava o equipamento. Assim, o Centro de Tênis recebe adaptações para abrigar esportes como futebol, por exemplo, mas também é utilizado para seu uso original estabelecido nas Olimpíadas (Tabela 1). 
Assim, embora a percepção de segurança dos usuários favoreça o uso do Centro de Tênis, este não é bem utilizado no período pós-jogos. Nesse sentido, a sua localização não contribui para o seu uso, tendo em vista que a maior parte dos seus usuários reside em áreas distantes do Parque Olímpico. Logo, o uso do Centro de Tênis no período pós-jogos poderia ser fomentado ao localizá-lo próximo aos locais de moradia dos potenciais usuários.

\section{Conclusões}

Com base nos resultados obtidos, o Velódromo, as Arenas Cariocas 1 e 3 e o Centro de Tênis, bem como seus entornos, são percebidos como seguros pelos quatro funcionários entrevistados, ainda que um deles tenha o conhecimento de fatos isolados de roubo. No mesmo sentido, dentre os 20 usuários, 19 os consideram seguros, indicando que a percepção de segurança favorece os usos destes equipamentos no período pós-jogos. Este resultado corrobora o de outro estudo onde a insegurança é citada como aspecto a ser melhorado no Parque Olímpico e seu entorno por apenas três moradores das imediações do Parque, dentre 41 entrevistados (Silva; Reis, 2018), e está em sintonia com aquele encontrado por Bertuzzi e Cardoso (2018), o qual indica a inexistência de ocorrências de crimes no Parque Olímpico, conforme 32 usuários entrevistados.

O Velódromo, a Arena Carioca 1 e o Centro de Tênis abrigam em maior quantidade campeonatos realizados pela Universidade Federal Fluminense, os quais reúnem programas de esporte e lazer para crianças e jovens do Rio de Janeiro, muitos de áreas de vulnerabilidade social e socioeconômica. Por esta razão, estes equipamentos atraem pessoas de bairros distantes da Barra da Tijuca. Dentre os 13 usuários entrevistados que utilizam estas três instalações, 10 moram entre $25 \mathrm{~km}$ e $40 \mathrm{~km}$ do Parque Olímpico, em áreas caracterizadas pelo baixo poder aquisitivo. Este resultado corrobora aqueles obtidos em um estudo (Silva; Reis, 2018), o qual indicou que os usuários do Parque Olímpico percorrem cerca de $40 \mathrm{~km}$ para chegar ao local. Todavia, alguns autores indicam que a distância máxima entre um equipamento de esporte e lazer e a residência deve ser de 500m (Prinz, 1986), 800m (Castello, 2008) ou, no máximo, 1000m (Pitts, 2004). Apesar das grandes distâncias percorridas, onze dos treze usuários consideram a localização destes equipamentos acessíveis por diferentes meios de locomoção (carro, ônibus, BRT e moto). Assim, a disponibilidade de transporte público e de via adequada (Avenida Transolímpica) reduziu problemas gerados pela distância entre os equipamentos e a moradia dos usuários.

Por outro lado, a Arena Carioca 3 estava sendo utilizada principalmente para treinos na academia e seus usuários eram, sobretudo, moradores do entorno, com suas residências localizadas até $2 \mathrm{~km}$ do Parque Olímpico, em áreas caracterizadas pelo alto poder aquisitivo. Apesar das atividades que eram realizadas pelo SESC nesta Arena serem benéficas para a população, estas foram interrompidas, sem previsão para seu retorno, impactando de modo negativo no uso da Arena Carioca 3.

Portanto, dentre os cinco equipamentos do Parque Olímpico do Rio de Janeiro estudados, quatro replicam os usos das Olimpíadas no período pós-jogos, ainda que outras atividades esportivas e não esportivas também ocorram nesses equipamentos. Assim, além de identificar os usos desses equipamentos no período pósjogos, este estudo evidencia a importância da presença de transporte público que favoreça o acesso aos equipamentos olímpicos. Contudo, a proximidade de tais equipamentos aos locais de moradia dos principais usuários, principalmente, daqueles de baixa renda, intensificaria seus usos após o término do megaevento. 


\section{XII $\quad$ SÃOPAULO15 $\sim 17 \cdot$ LISBOA $25 \sim 26$ JUN 2020

Adicionalmente, confirma-se a importância da segurança nos equipamentos olímpicos e seu entorno para seus usos no período pós-jogos. Ainda, os resultados obtidos podem contribuir para reforçar a importância da consideração do uso pós-jogos de equipamentos olímpicos, primeiramente, pela população mais carente, e, logo, que o planejamento da localização destes equipamentos deve ter em conta a segurança e os locais de moradia desta população.

\section{Referências}

AZZALI, S. (2017). Queen Elizabeth Olympic Park: an assessment of the 2012 London Games Legacies. City, Territory and Architecture, 4, 11, 1-12.

BERTUZZI, F. B.; CARDOSO, G. T. (2018). A paisagem urbana frente ao uso e apropriação do ambiente construído. $5^{\circ}$ Colóquio Ibero-Americano: Paisagem Cultural, Patrimônio e Projeto. Belo Horizonte, 26-28 setembro.

CASHMAN, R. (1998). Olympic legacy in an Olympic city: monuments, museums and memory. Fourth International Symposium for Olympic Research. London, Ontario, 1-3 outubro.

CASHMAN, R. (2012). Impact of the Games on Olympic Host Cities. Barcelona: Centre d'Estudis Olímpics (UAB). International Chair in Olympism (IOC-UAB).

CASTELLO, I. (2008). Bairros, loteamentos e condomínios: elementos para o projeto de novos territórios habitacionais. Porto Alegre: UFRGS.

COMITÊ DE CANDIDATURA RIO 2016. (2009a). Dossiê de candidatura do Rio de Janeiro a sede dos Jogos Olímpicos e Paralímpicos de 2016 - vol.1. Rio de Janeiro.

COMITÊ DE CANDIDATURA RIO 2016. (2009b). Dossiê de candidatura do Rio de Janeiro a sede dos Jogos Olímpicos e Paralímpicos de 2016 - vol.3. Rio de Janeiro.

DAVIES, L. E. (2012). Beyond the Games: Regeneration legacies and London 2012. Leisure Studies, 31, 3 , 309-337.

ESSEX, S.; CHALKLEY, B. (2003). The infrastructural legacy of the Summer and Winter Olympic Games: a comparative analysis. En: SPÀ, M. DE M.; KENNETT, C.; PUIG, N. (Eds.), The Legacy of the Olympic Games 1984-2000 (94-101). Lausanne: Documents of the Museum, International Olympic Committee.

FRANCIS, M. (2003). Urban Open Space: Designing For User Needs. Washington: Island Press.

IOC. (2015). Olympic Games Framework. Lausana: IOC.

IOC. (2017). Legacy Strategic Approach Moving Forward. Lausana: IOC.

JACOBS, J. (2014). Morte e vida de grandes cidades. São Paulo: Editora WMF Martins Fontes.

MASCARENHAS, G. (2014). Cidade mercadoria, cidade-vitrine, cidade turística: a espetacularização do urbano nos megaeventos esportivos. Caderno Virtual de Turismo, 14, 52-65.

MONTEIRO, P.; COSENTINO, R. (2017). Rio 2016 : projeto, orçamento e (des) legados olímpicos. Rio de Janeiro: Fundação Heinrich Böll Brasil.

PANAGiotopouloU, R. (2014). The legacies of the Athens 2004 Olympic Games: A bitter-sweet burden. Contemporary Social Science, 9, 2, 173-195.

PASQUOTTO, G. B. (2016). Uso e ocupação do solo na Barra da Tijuca e o espraiamento de sua "marca". V Colóquio Internacional sobre o Comércio e a Cidade: uma relação de origem. São Paulo, 21-24 março. 


\section{SÃOPAULO15 17 LISBOA $25 \sim 26$ JUN 2020}

PITTS, A. (2004). Planning and Design Strategies for Sustainability and Profit. Oxford: Architectural Press.

PREFEITURA DO RIO DE JANEIRO. (2014). Rio 2016: Jogos Olímpicos e legado. Cadernos de Políticas Públicas. Rio de Janeiro, 1-35.

PRINZ, D. (1986). Planificación y Configuración Urbana. México: Ediciones G. Gill S.A. de C.V.

REIS, A.; LAY, M.C. (1995). As Técnicas de APO Como Instrumento de Análise Ergonômica do Ambiente Construído - Curso Avaliação Pós-Ocupação. III Encontro Nacional e I Encontro Latino-Americano de Conforto no Ambiente Construído, Gramado, 4-7 julho.

RITCHIE, J. R. (2000). Turning 16 days into 16 years through Olympic legacies. Event Management, 6, 11, 155-165.

RODRIGUES, R. P.; PINTO, L. M. S. DE M. (2008). Subsídios para pensar os legados de megaeventos esportivos em seus tempos presente, passado e futuro. En: RODRIGUES, R. P.; TERRA, L. M.; DACOSTA, L. P. (Eds.), Legados de megaeventos esportivos (21-25). Brasília: Ministério do Esporte. Governo Federal.

ROULT, R.; LEFEBVRE, S. (2010). Planning and reconversion of olympic heritages: The montreal olympic stadium. International Journal of the History of Sport, 27, 16-18, 2731-2747.

SILVA, G.; REIS, A. T. (2018). Localização e usos de equipamentos olímpicos: uma análise exploratória pósjogos. V Encontro da Associação Nacional de Pesquisa e Pós-Graduação em Arquitetura e Urbanismo. Salvador, 13-19 outubro.

SMITH, A. (2014). "De-Risking" East London: Olympic Regeneration Planning 2000 - 2012. European Planning Studies, 9, 22, 1919-1939.

TOOHEY, K. (2008). The Sydney Olympics: striving for legacies - overcoming short-term disappointments and long-term deficiencies. The International Journal of the History of Sport, 25, 14, 1953-1971.

\section{Fontes eletrônicas}

http:// www.ibge.gov.br (consulta: 06/02/2020). 